\title{
Association of ZNF331 and WIF1 methylation in peripheral blood leukocytes with the risk and prognosis of gastric cancer
}

Chuang Nie ${ }^{1}$, Xu Han ${ }^{1}$, Rongrong Wei ${ }^{1}$, Anastasiia Leonteva ${ }^{1}$, Jia Hong ${ }^{1}$, Xinyu Du ${ }^{1}$, Jing Wang ${ }^{1}$, Lin Zhu ${ }^{1}$, Yashuang Zhao ${ }^{1}$, Yingwei Xue ${ }^{2}$, Haibo Zhou ${ }^{1 *}$ (D) and Wenjing $\operatorname{Tian}^{1{ }^{*}}$ (i)

\begin{abstract}
Background: Peripheral blood leukocyte (PBL) DNA methylation may serve as a surrogate marker to evaluate the susceptibility to and prognosis of gastric cancer (GC). In this study, blood-derived DNA methylation levels of two tumour-related genes, namely, ZNF331 and WIF1, and their impacts on the risk and prognosis of GC were evaluated.

Methods: In total, 398 GC cases and 397 controls were recruited for the study. Then, all cases were followed up for 5 years. ZNF331 and WIF1 promoter methylation status in PBLs was measured using a methylation-sensitive highresolution melting method. Logistic and Cox regression models were used to analyse the correlation between gene methylation and the risk and prognosis of GC. Confounders were balanced through propensity score (PS) matching.

Results: High ZNF331 methylation significantly decreased GC risk after PS adjustment (OR $=0.580,95 \%$ Cl: $0.375-$ $0.898, P=0.015)$, which also presented in males ( $\mathrm{OR}=0.577,95 \% \mathrm{Cl}: 0.343-0.970, P=0.038)$. However, WIF1

methylation was not associated with GC risk. Additionally, significant combined effects between ZNF331 methylation and the intake of green vegetables and garlic were observed $(\mathrm{OR}=0.073,95 \% \mathrm{Cl}: 0.027-0.196, P<0.001$ and $\mathrm{OR}=$ $0.138,95 \%$ Cl: $0.080-0.238, P<0.001$, respectively). Furthermore, ZNF331 and WIF1 methylation had no impact on the prognosis of GC.
\end{abstract}

Conclusion: ZNF331 methylation in PBLs may affect GC risk in combination with the consumption of green vegetables and garlic and may act as a potential biomarker of GC.

Keywords: Gastric cancer, DNA methylation, Peripheral blood leukocytes, Propensity score

\section{Background}

Gastric cancer (GC) is an aggressive disease that is the fifth most prevalent malignancy and the third leading cause of cancer-related deaths worldwide [1]. Multiple factors are involved in the development of GC, including

\footnotetext{
*Correspondence: twj8267@sina.com; youdeng23@163.com

1 Department of Epidemiology, School of Public Health, Harbin Medical University, Harbin, 157 Baojian Road, Harbin 150081, Heilongjiang Province, People's Republic of China

Full list of author information is available at the end of the article
}

genetic, epigenetic and environmental factors [2]. Epigenetics refers to heritable changes in phenotypes that occur without alterations in DNA nucleoside sequences [3]. Abnormal DNA methylation is an extensively studied epigenetic modification that mainly includes two different forms: genome-wide changes and regional variations [4, 5]. Genome-wide methylation changes, known as global DNA hypomethylation, can contribute to carcinogenesis by inducing the formation of repressive chromosomal structures [6]. Regional methylation variations, particularly

(c) The Author(s). 2021, corrected publication 2021. Open Access This article is licensed under a Creative Commons Attribution 4.0 International License, which permits use, sharing, adaptation, distribution and reproduction in any medium or format, as long as you give appropriate credit to the original author(s) and the source, provide a link to the Creative Commons licence, and indicate if changes were made. The images or other third party material in this article are included in the article's Creative Commons licence, unless indicated otherwise in a credit line to the material. If material is not included in the article's Creative Commons licence and your intended use is not permitted by statutory regulation or exceeds the permitted use, you will need to obtain permission directly from the copyright holder. To view a copy of this licence, visit http://creativecommons.org/ licenses/by/4.0/. The Creative Commons Public Domain Dedication waiver (http://creativecommons.org/publicdomain/zero/1. 0/) applies to the data made available in this article, unless otherwise stated in a credit line to the data. 
aberrant hypermethylation in promoter $\mathrm{CpG}$ islands, have been relatively more studied and can lead to the silencing of tumour suppressor genes in almost all cancer types [7]. However, losses of DNA methylation at normally methylated $\mathrm{CpG}$ islands were virtually the first recognized epigenetic abnormality that can lead to gene activation [5]. DNA methylation changes have emerged as having promising diagnostic, prognostic, and predictive value in cancer [8]. Additionally, epigenetic mechanisms may function as an interface between environmental factors and the genome. Mounting studies have suggested that exposure to environmental and lifestyle factors can affect methylation status and thus promote tumourigenesis [9-11].

Zinc-finger protein 331 (ZNF331) belongs to the zincfinger gene family, encoding a zinc finger protein that contains a Kruppel-associated box domain that plays an essential part in the transcriptional regulation process [12, 13]. Aberrant promoter hypermethylation of ZNF331 has been demonstrated to epigenetically promote gastric carcinogenesis through the downregulation of its expression [14]. In addition, several other studies in tissue samples supported that ZNF331 methylation could function as a potential biomarker in gastrointestinal malignancies, particularly for colorectal cancer detection and prognosis prediction [15-17].

Wnt-inhibitory factor-1 (WIF1) is a secreted repressor that can directly bind to various Wnt ligands and inhibit their activities $[18,19]$. Promoter hypermethylation of WIF1, leading to silencing of its expression and subsequent aberrant activation of the Wnt signalling pathway, was reported to participate in gastric tumourigenesis [20]. In addition, WIF1 hypermethylation has been revealed to correlate with poor survival in non-small-cell lung cancer [21], oesophageal squamous cell carcinoma [22], and chondrosarcoma [23].

Most of the previous studies have focused on tissuederived DNA to investigate the association between gene methylation and cancer risks and prognoses. However, as target tissue of interest is often unobtainable, peripheral blood may serve as an ideal surrogate for the exploration of cancer biomarkers due to its non-invasiveness and high accessibility [24]. DNA methylation changes can be observed in most tumours of all organ systems, which indicates that they may arise everywhere in the body, including peripheral blood leukocytes (PBLs) [25]. To date, several studies have demonstrated the impact of blood-derived DNA methylation on the susceptibility to various cancer types, including GC [26-28]. Therefore, this population-based study was conducted to investigate the correlations of environmental exposures, ZNF331 and WIF1 methylation in PBLs, and their interactions with the incidence of GC. Furthermore, all GC patients were followed up to measure the prognostic effect of the genes.

\section{Methods}

\section{Study population}

A total of 398 GC patients pathologically diagnosed from 2010 through 2012 were selected as cases. A total of 397 non-cancerous controls were recruited during the same period, including patients with non-digestive diseases and healthy individuals who received health examinations. The source of these subjects and specific inclusion and exclusion criteria have been described before [29]. Every participant provided written informed consent and donated $5 \mathrm{ml}$ of blood samples. The study was approved by the Human Research and Ethics Committee of Harbin Medical University and conducted in accordance with the Declaration of Helsinki.

\section{Data collection}

All subjects completed a face-to-face questionnaire to obtain demographic features, family history of GC, lifestyle, and dietary habits. The questions on food frequency were modified from a previous study on the basis of eating patterns in northern China [30]. The clinicopathological data were obtained from the electronic medical record system. All cases were followed up for 5 years by telephone interview to collect information on the cause of death and date. Overall survival was considered the primary outcome. Finally, 375 GC patients were available for the survival analysis after excluding patients who lacked follow-up data. Among them, 192 patients died, 139 patients survived, and 44 patients were lost to follow-up. Helicobacter infection status was measured by ELISA (IBL, Germany).

\section{Methylation detection}

Genomic DNA was extracted with a QIAamp DNA Blood Mini Kit (Qiagen), and then bisulfite modification was performed using an EpiTect Fast DNA Bisulfite Kit in accordance with the manufacturer's protocols. DNA purity and concentrations were quantified by spectrophotometric measurement. Then, primer pairs of the two candidate genes were designed, and Additional file 1 (Table S1) shows the primer sequences and detailed information on the reaction conditions. PCR and methylationsensitive high-resolution melting (MS-HRM) analysis were conducted on a Roche 480 II (Germany). Methylation status was determined using Gene Scanning software (version 2.0).

A series of normalized curves were constructed by mixing DNA methylated standards (100\% methylated and $0 \%$ methylated DNA, Zymo Research). The corresponding sequence information of the DNA methylated standards is shown in Additional file 1 (Table S1). PCRgrade water was used as a blank control in every experimental run. Figure 1 presents the standard melting curves and melting peaks. According to the receiver 


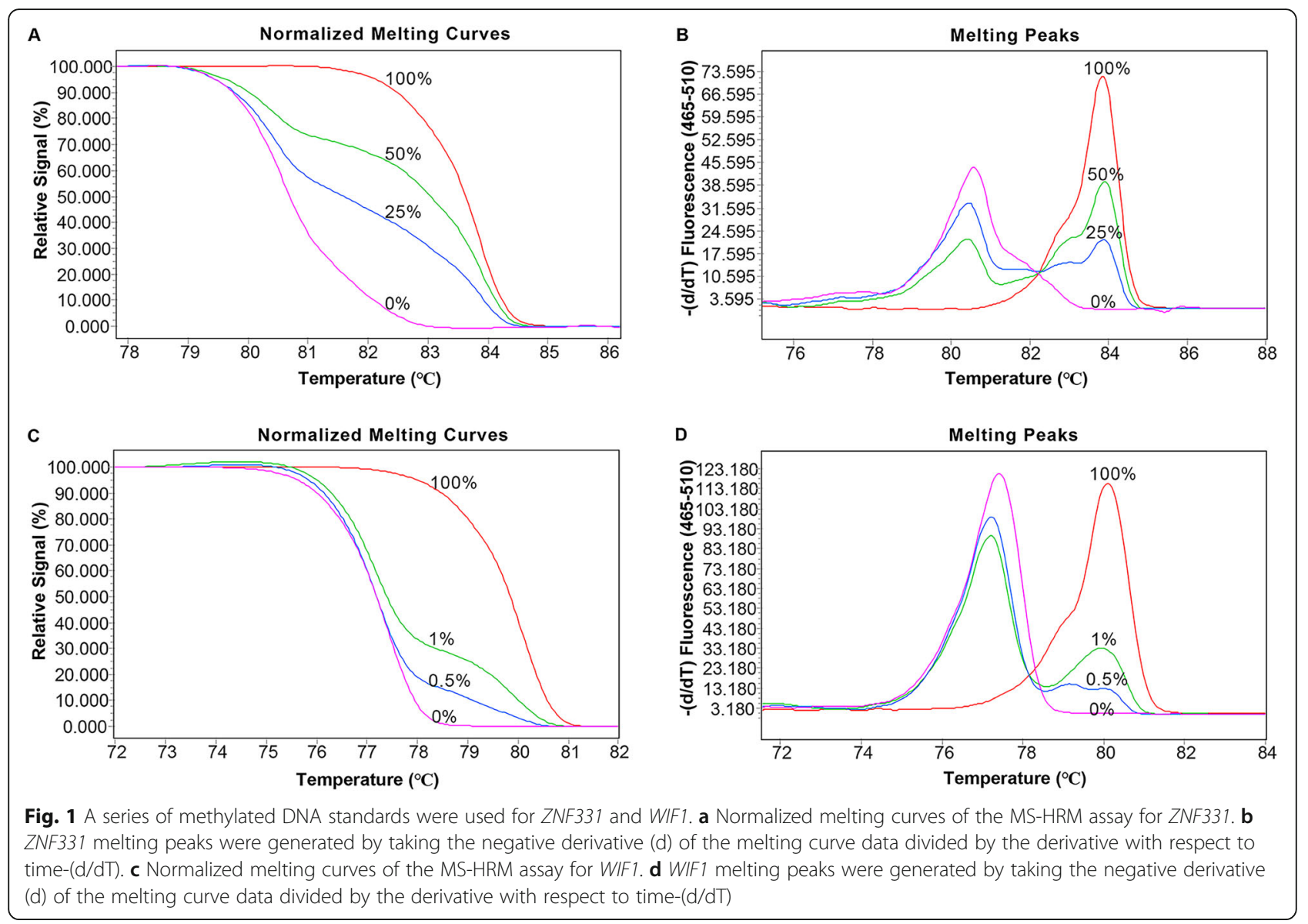

operating characteristic curve, 50\% methylated DNA was used as the optimal cut-off value for ZNF331 to determine high methylation $(\mathrm{Hm})$ or low methylation $(\mathrm{Lm})$ (Additional file 2: Figure S1). For the definition of WIF1 methylation status, $\mathrm{Hm}$ refers to a combination of homogeneous methylation (Hom) and heterogeneous methylation (Hem), and Lm is consistent with $0 \%$ methylated DNA (Additional file 3: Figure S2). Compared with Hom, Hem is characterized by earlier melting with a complex profile due to the formation of heteroduplexes [31]. The methylation status of the two genes in all samples is shown in Additional file 4 (Figure S3).

\section{Statistical analysis}

The chi-square test was applied to examine the betweengroup differences for categorical variables, and Student's $t$ test was applied for continuous variables. Missing data less than $30 \%$ were addressed by multiple imputation. Logistic regression analysis was utilized to explore the correlation of DNA methylation and environmental exposures with GC. The odds ratios (ORs) and 95\% confidence intervals (CIs) were adjusted by propensity scores (PSs). Geneenvironment interactions were evaluated through multivariable logistic regression models. The combined effects of DNA methylation and environmental exposure were assessed by crossover analysis. An internal validation was further performed by repeating subsampling of two-thirds of the population 1000 times without replacement, and the average results from the internal validation datasets were calculated. Survival curves were generated using the Kaplan-Meier method. Cox regression models were applied to compute hazard ratios (HRs) and 95\% CIs. The analyses were completed by SPSS 23.0. R-3.1.3 for Windows with PS matching 3.04 packages was applied for PS analysis. $P<0.05$ was considered statistically significant.

\section{Results}

Characteristics of the subjects

Table 1 shows the demographic features of the study population. The differences in body mass index (BMI), occupation and monthly income between cases and controls were statistically significant $(P<0.05)$. In contrast to the controls, the GC patients exhibited a larger proportion of GC family history $(P<0.05)$.

\section{The effects of environmental exposures on GC risk}

The correlations of environmental exposures with GC risk are presented in Additional file 5 (Table S2). After 
Table 1 The basic demographic characteristics of the subjects

\begin{tabular}{|c|c|c|c|c|}
\hline \multirow[t]{2}{*}{ Variable } & & \multirow{2}{*}{$\begin{array}{l}\text { Cases }(\%) \\
n=398\end{array}$} & \multirow{2}{*}{$\begin{array}{l}\text { Controls (\%) } \\
n=397\end{array}$} & \multirow[t]{2}{*}{$P$} \\
\hline & & & & \\
\hline \multirow[t]{2}{*}{ Sex } & Male & $301(75.6)$ & $300(75.6)$ & 0.984 \\
\hline & Female & $97(24.4)$ & $97(24.4)$ & \\
\hline \multirow[t]{3}{*}{ Age $($ mean $\pm S D)$} & & $58.22 \pm 11.35$ & $58.69 \pm 10.50$ & 0.549 \\
\hline & $\geq 60$ & $187(47.0)$ & $193(48.6)$ & 0.646 \\
\hline & $<60$ & $211(53.0)$ & $204(51.4)$ & \\
\hline \multirow[t]{2}{*}{ BMI $\left(\mathrm{kg} / \mathrm{m}^{2}\right)$} & $\geq 24.00$ & $125(31.4)$ & $194(48.9)$ & $<0.001^{*}$ \\
\hline & $<24.00$ & $273(68.6)$ & $203(51.1)$ & \\
\hline \multirow[t]{2}{*}{ Occupation } & White Collar & $148(37.2)$ & $41(10.3)$ & $<0.001^{*}$ \\
\hline & Blue Collar & $250(62.8)$ & $356(89.7)$ & \\
\hline \multirow[t]{2}{*}{ Monthly income (RMB/Per capita) } & $\geq 1000$ & $258(64.8)$ & $213(53.7)$ & $0.001^{*}$ \\
\hline & $<1000$ & $140(35.2)$ & $184(46.3)$ & \\
\hline \multirow[t]{2}{*}{ Family history of GC } & Yes & $56(14.1)$ & $10(2.5)$ & $<0.001^{*}$ \\
\hline & No & $342(85.9)$ & $387(97.5)$ & \\
\hline
\end{tabular}

BMI body mass index, GC gastric cancer

* Statistically significant

backward conditional selection analysis, our data showed that infection with $H$. pylori, irregular diet, alcohol consumption, intake of freshwater fish, dairy products, food left overnight, salted food, fried food and drinking of unsanitary water (water from rivers and wells) could significantly increase the risk of GC $(P<0.05)$. Conversely, high intakes of green vegetables, garlic, eggs, refrigerated food and beef and mutton were correlated with a decreased risk of $\mathrm{GC}(P<0.05)$. Consistent results were observed in the internal validation population (Additional file 6: Table S3).

\section{The impact of ZNF331 and WIF1 methylation on GC risk} Compared with Lm, ZNF331 Hm was significantly associated with a decreased risk of GC after PS adjustment $(\mathrm{OR}=$ 0.580, 95\% CI: $0.375-0.898, P=0.015)$. However, WIF1 methylation was not associated with GC risk (Table 2).

\section{Subgroup analysis}

When the analysis was stratified by age, ZNF331 Hm was marginally correlated with decreased GC risk among both the younger and older groups $(\mathrm{OR}=0.523,95 \% \mathrm{CI}$ : $0.265-1.030, P=0.061$ and $\mathrm{OR}=0.549$, 95\% CI: $0.296-$ $1.018, P=0.057$, respectively). Subgroup analysis by sex showed that ZNF331 Hm conferred a decreased GC risk only in males $(\mathrm{OR}=0.577,95 \% \mathrm{CI}: 0.343-0.970, P=$ 0.038). In addition, subgroup analysis by $H$. pylori infection revealed a marginal association between ZNF331 $\mathrm{Hm}$ and $\mathrm{GC}$ in the negative $H$. pylori infection group (OR $=0.474,95 \%$ CI: $0.220-1.023, P=0.057)$. For WIF1, there was a marginal correlation only in younger individuals ( $<60$ years, OR $=0.470,95 \%$ CI: $0.219-1.007, P=$ 0.052) (Additional file 7: Table S4).

\section{The combined effects of ZNF331 and WIF1 (ZW) methylation on GC risk}

To evaluate the combined effect between ZNF331 and WIF1 methylation, both ZNF331 and WIF1 Lm (ZW 1) was defined as a reference; likewise, either ZNF331 or WIF1 $\mathrm{Hm}$ was defined as $Z W 2$, and both ZNF331 and WIF1 $\mathrm{Hm}$ were regarded as $Z W 3$. The correlation between the newly defined $Z W$ methylation and GC was

Table 2 Association between the methylation status of ZNF331 and WIF1 and GC risk

\begin{tabular}{llllllllll}
\hline \multicolumn{2}{l}{ Methylation status } & Case (\%) & Control (\%) & Crude OR(95\% Cl) & $\boldsymbol{P}$ & OR $^{\mathbf{a}}(\mathbf{9 5 \%} \mathrm{Cl})$ & $\boldsymbol{P}$ & OR $^{\mathbf{b}}(\mathbf{9 5 \%} \mathrm{Cl})$ & $\boldsymbol{P}$ \\
\hline ZNF331 & $\mathrm{Hm}$ & $162(43.8)$ & $221(60.9)$ & $0.500(0.373-0.672)$ & $<0.001^{*}$ & $0.585(0.382-0.896)$ & $0.014^{*}$ & $0.580(0.375-0.898)$ & $0.015^{*}$ \\
& $\mathrm{Lm}$ & $208(56.2)$ & $142(39.1)$ & 1.000 & & 1.000 & 1.000 \\
WIF1 & $\mathrm{Hm}$ & $88(24.0)$ & $134(35.7)$ & $0.567(0.412-0.781)$ & $0.001^{*}$ & $0.715(0.450-1.137)$ & 0.157 & $0.714(0.445-1.146)$ & 0.162 \\
& $\mathrm{Lm}$ & $279(76.0)$ & $241(64.3)$ & 1.000 & & 1.000 & 1.000 \\
\hline
\end{tabular}

$\mathrm{Lm}$ low methylation, $\mathrm{Hm}$ high methylation, $\mathrm{Cl}$ confidence interval, $\mathrm{OR}$ odds ratio, $\mathrm{GC}$ gastric cancer

* Statistically significant

a Adjusted for age, sex, BMI, monthly income, occupation, family history of GC, H. pylori infection, green vegetables, garlic, beef and mutton, freshwater fish, fried food, refrigerated food, egg, food left overnight, alcohol consumption, water, salted food, dairy products and irregular diet

${ }^{\mathrm{b}}$ Adjusted for propensity score of all variables 
explored. As presented in Table 3, $Z W$ methylation was significantly correlated with the risk of GC after PS adjustment $(\mathrm{OR}=0.419,95 \% \mathrm{CI}: 0.286-0.614, P<0.001$ and $\mathrm{OR}=0.274,95 \%$ CI: $0.158-0.474, P<0.001$ for $Z W$ 2 and $Z W 3$, respectively). Moreover, the strength of the correlation significantly decreased $(P$-trend $<0.001)$.

\section{Correlations between environmental exposures and gene methylation}

$H$. pylori infection decreased the risk of ZNF331 methylation $(\mathrm{OR}=0.645,95 \% \mathrm{CI}: 0.477-0.872, \quad P=0.004)$. Additionally, alcohol consumption and irregular diet were correlated with a decreased risk of WIF1 methylation $(\mathrm{OR}=0.724,95 \% \mathrm{CI}: 0.527-0.994, P=0.045$ and $\mathrm{OR}=0.648,95 \% \mathrm{CI}: 0.443-0.946, P=0.025$, respectively) (Additional file 8: Table S5).

\section{The effects of gene-environment and gene-gene interactions on $\mathrm{GC}$ risk}

ZNF331 methylation and high intakes of green vegetables and garlic had significant combined effects on GC risk $(\mathrm{OR}=0.073,95 \% \mathrm{CI}: 0.027-0.196, P<0.001$ and $\mathrm{OR}=0.138,95 \% \mathrm{CI}: 0.080-0.238, P<0.001$, respectively) (Table 4), and the internal validation further demonstrated these combined effects (Additional file 9: Table S6). However, there were no interactions between ZNF331 methylation and environmental exposure (Table 4 and Additional file 10: Table S7). WIF1 methylation and intake of refrigerated food exhibited a significant combined effect $(\mathrm{OR}=0.227,95 \% \mathrm{CI}$ : $0.136-0.380, P<$ 0.001 ), and their interaction displayed a synergistic effect on the risk of $\mathrm{GC}(\mathrm{OR}=2.588,95 \% \mathrm{CI}$ : 1.097-6.105, $P=$ 0.030) (Additional file 11: Table S8). In addition, no interaction was observed between ZNF331 and WIF1 methylation and $\mathrm{GC}$ risk $(P>0.05)$ (Additional file 12 : Table S9).

\section{Gene methylation and GC prognosis}

The associations of demographic and clinicopathological features with GC prognosis are shown in Additional files 13 and 14 (Tables S10 and S11, respectively).
Tumour size, tumour node metastasis (TNM) stage, carcinoembryonic antigen (CEA) and carbohydrate antigen 19-9 (CA 19-9) levels were significantly correlated with GC prognosis after adjusting for age, sex and BMI $(P<$ 0.05). Further backward conditional selection suggested that only TNM stage $(\mathrm{HR}=2.518,95 \% \mathrm{CI}: 1.197-5.297$, $P=0.015$ and $\mathrm{HR}=5.629,95 \% \mathrm{CI}: 2.855-11.102, P<$ 0.001 for TNM stages III and IV, respectively) and tumour size $(\mathrm{HR}=1.518,95 \% \mathrm{CI}: 1.137-2.027, \quad P=$ 0.005 ) were independent factors for GC prognosis (Additional file 15: Table S12).

The potential impact of ZNF331 and WIF1 methylation on the prognosis of GC was further investigated. However, no significant associations of methylation status of the two genes with GC prognosis were found $(P>$ 0.05) (Table 5). The survival curves are shown in Additional file 16 (Figure S4). When the analysis was stratified by sex, a marginal correlation between WIF1 methylation and GC prognosis was found after multivariable adjustment $(\mathrm{HR}=0.643,95 \% \mathrm{CI}$ : 0.411-1.008, $P=$ 0.054 and $\mathrm{HR}=1.878,95 \% \mathrm{CI}: 0.952-3.705, P=0.069$ for males and females, respectively), whereas no association was found after PS adjustment. Stratified analyses according to age, $H$. pylori infection, TNM stage and tumour size suggested no significant association in any subgroup $(P>0.05)$ (Additional file 17: Table S13).

\section{Discussion}

Aberrant DNA methylation, which induces abnormal expression of cancer-related genes, is one of the most common epigenetic mechanisms in tumour development and progression. It is known that DNA methylation changes during carcinogenesis are not confined to the target cells of the tumour tissue itself and that the immune system, such as leukocytes, may undergo specific methylation variations in the genome due to immune responses in early stages [32]. Since the sampling of peripheral blood is non-invasive and easy, assessing the DNA methylation status in PBLs may serve as a novel tool to determine cancer risks and prognoses. Therefore, we focused on the methylation of two tumour

Table 3 Combined effects of ZNF331 and WIF1 (ZW) methylation and GC risk

\begin{tabular}{|c|c|c|c|c|c|c|c|c|c|c|}
\hline \multicolumn{2}{|c|}{ Methylation status } & \multirow{2}{*}{$\frac{\text { Case (\%) }}{151(44.5)}$} & \multirow{2}{*}{$\begin{array}{l}\text { Control (\%) } \\
79(23.2)\end{array}$} & \multirow{2}{*}{$\begin{array}{l}\text { Crude OR(95\% Cl) } \\
1.000\end{array}$} & \multirow[t]{2}{*}{$P$} & \multirow{2}{*}{$\frac{\mathrm{OR}^{\mathrm{a}}(95 \% \mathrm{Cl})}{1.000}$} & \multirow[t]{2}{*}{$P$} & \multirow{2}{*}{$\frac{\mathrm{OR}^{\mathrm{b}}(95 \% \mathrm{Cl})}{1.000}$} & \multirow[t]{2}{*}{$P$} & \multirow[t]{2}{*}{$P$-trend ${ }^{\mathrm{C}}$} \\
\hline$Z W$ & 1 & & & & & & & & & \\
\hline & 2 & $154(45.4)$ & $193(56.6)$ & $0.417(0.296-0.589)$ & $<0.001^{*}$ & $0.471(0.285-0.776)$ & $0.003^{*}$ & $0.419(0.286-0.614)$ & $<0.001^{*}$ & \\
\hline & 3 & $34(10.0)$ & $69(20.2)$ & $0.258(0.158-0.422)$ & $<0.001^{*}$ & $0.407(0.202-0.821)$ & $0.012^{*}$ & $0.274(0.158-0.474)$ & $<0.001^{*}$ & $<0.001^{*}$ \\
\hline
\end{tabular}

1: Both ZNF331 and WIF1 were low methylated

2: One low and the other high

3: Both ZNF331 and WIF1 were high methylated

$\mathrm{Cl}$ confidence interval, $O R$ odds ratio, GC gastric cancer

* Statistically significant

${ }^{a}$ Adjusted for age, sex, BMI, monthly income, occupation, family history of GC, H. pylori infection, green vegetables, garlic, beef and mutton, freshwater fish, fried

food, refrigerated food, egg, food left overnight, alcohol consumption, water, salted food, dairy products and irregular diet

${ }^{\mathrm{b}}$ Adjusted for propensity score of all variables

c The Cochran-Armitage trend test 
Table 4 Effects of the combination and interaction between environmental factors and ZNF331 methylation status on GC risk

\begin{tabular}{|c|c|c|c|c|c|c|}
\hline \multirow{3}{*}{$\begin{array}{l}\text { Environmental } \\
\text { factors }\end{array}$} & \multicolumn{6}{|c|}{ ZNF331 methylation status } \\
\hline & \multicolumn{2}{|l|}{$\mathrm{Hm}$} & \multicolumn{2}{|l|}{$\mathrm{Lm}$} & \multicolumn{2}{|l|}{ Interactions } \\
\hline & $\mathrm{OR}^{\mathrm{a}}(95 \% \mathrm{Cl})$ & $P$ & $\mathrm{OR}^{\mathrm{a}}(95 \% \mathrm{Cl})$ & $P$ & $\mathrm{OR}^{\mathrm{b}}(95 \% \mathrm{Cl})$ & $P$ \\
\hline \multicolumn{7}{|c|}{ Green vegetables (g/week) } \\
\hline$\geq 250$ & $0.073(0.027-0.196)$ & $<0.001^{*}$ & $0.126(0.046-0.340)$ & $<0.001^{*}$ & $3.080(0.911-10.406)$ & 0.070 \\
\hline$<250$ & $0.188(0.058-0.603)$ & $0.005^{*}$ & 1.000 & & & \\
\hline \multicolumn{7}{|c|}{ Garlic (times/week) } \\
\hline$\geq 1$ & $0.138(0.080-0.238)$ & $<0.001^{*}$ & $0.352(0.211-0.586)$ & $<0.001^{*}$ & $0.680(0.328-1.411)$ & 0.300 \\
\hline$<1$ & $0.576(0.383-0.868)$ & $0.008^{*}$ & 1.000 & & & \\
\hline
\end{tabular}

$\mathrm{Lm}$ low methylation, $\mathrm{Hm}$ high methylation, $\mathrm{Cl}$ confidence interval, $\mathrm{OR}$ odds ratio, GC gastric cancer

* Statistically significant

${ }^{a}$ Combined effects adjusted for propensity score of age, sex, BMI, occupation, monthly income and family history of GC

${ }^{b}$ Interactions adjusted for propensity score of age, sex, BMI, occupation, monthly income and family history of GC

suppressor genes derived from PBLs and the impact on the risk and prognosis of GC in this population-based study.

Our study first demonstrated that subjects with ZNF331 Hm had a significantly lower risk of GC, and the effect was confirmed in a PS adjusted model that included all the other variables in the study. This finding was intriguing in that the lower ZNF331 promoter methylation level in GC cases is inconsistent with previous reports that ZNF331 serves as a tumour suppressor gene that is hypermethylated and downregulated in several types of cancer tissues, including GC [14], colorectal cancer [15-17], and oesophageal squamous cell carcinoma [33]. However, it has been reported that leukocytederived DNA methylation changes at specific loci may not reflect those in target tissues [24], which means there was little correlation between the two origins. Some studies further hypothesized that DNA methylation changes in PBLs may arise from alterations in the leukocyte subpopulation, which was a response of immune surveillance to the appearance of tumours [34]. In addition to the possibility that DNA methylation exhibits high tissue specificity, it is also worth noting that the differentially methylated region in this study was located at -701 to -573 relative to the transcription start site (NM_001079907, hg19), which was different from the target regions in previous reports. Numerous studies have indicated that global DNA hypomethylation in
PBLs, measured as the methylation status of repetitive sequences (such as LINE-1), is associated with GC risk $[35,36]$. In addition, it was reported that hypomethylation of normally methylated promoters is associated with global hypomethylation and independent of frequent promoter hypermethylation [37]. We therefore hypothesized that significant global hypomethylation might disrupt certain protective mechanisms of methylated promoter regions and subsequently induce promoter hypomethylation. In addition, no differences in WIF1 promoter methylation levels were found between GC cases and controls in this study, while previous reports have shown WIF1 hypermethylation in circulating DNA of colorectal cancer patients [38,39] and in tissue-derived DNA of several types of tumours, including GC [20]. Interestingly, in our previous work using the same detection method, we demonstrated expected hypermethylation of WIF1 in colorectal tumour tissues [40], which to some extent indicated the tissue specificity of DNA methylation. In short, the methylation of ZNF331 and WIF1 we observed was limited to PBLs, which may not be extended to gastric tumour tissues. More efforts are needed to elucidate the underlying molecular mechanisms involved in these findings, especially for the nature and origin of DNA methylation in PBLs.

Epidemiological studies have suggested that environmental factors such as $H$. pylori infection, heavy alcohol consumption, cigarette smoking, salty food intake, and

Table 5 Association between the methylation status of ZNF331 and WIF1 and GC prognosis

\begin{tabular}{|c|c|c|c|c|c|c|c|c|}
\hline \multicolumn{2}{|c|}{ Methylation status } & \multirow{2}{*}{$\frac{\text { Case(\%) }}{157(45.1)}$} & \multirow{2}{*}{$\frac{\text { Crude HR(95\%Cl) }}{0.960(0.713-1.293)}$} & \multirow{2}{*}{$\frac{P}{0.788}$} & \multirow{2}{*}{$\begin{array}{l}\mathbf{H R}^{\mathbf{a}} \mathbf{( 9 5 \% C l )} \\
1.088(0.799-1.483)\end{array}$} & \multirow{2}{*}{$\frac{P}{0.592}$} & \multirow{2}{*}{$\begin{array}{l}\mathbf{H R}^{\mathbf{b}} \mathbf{( 9 5 \% \mathbf { C l } )} \\
1.052(0.759-1.457)\end{array}$} & \multirow{2}{*}{$\frac{P}{0.762}$} \\
\hline ZNF331 & $\mathrm{Hm}$ & & & & & & & \\
\hline & $\mathrm{Lm}$ & $191(54.9)$ & 1.000 & & 1.000 & & 1.000 & \\
\hline \multirow[t]{2}{*}{ WIF1 } & $\mathrm{Hm}$ & $84(23.9)$ & $0.892(0.625-1.272)$ & 0.528 & $0.852(0.592-1.225)$ & 0.386 & $0.830(0.568-1.215)$ & 0.338 \\
\hline & $\mathrm{Lm}$ & $267(76.1)$ & 1.000 & & 1.000 & & 1.000 & \\
\hline
\end{tabular}

$\mathrm{Lm}$ low methylation, $\mathrm{Hm}$ high methylation, $\mathrm{Cl}$ confidence interval, $H R$ hazard ratio, GC gastric cancer

${ }^{\text {a }}$ Adjusted for age, sex, BMI, tumor size, TNM stage

${ }^{\mathrm{b}}$ Adjusted for propensity score of all variables 
consumption of poorly preserved, pickled or contaminated foods are associated with GC [2, 41-43]. Environmental factors, including dietary habits, play important roles in carcinogenesis through the modification of DNA methylation [11]. Thus, the interactions between gene methylation and dietary factors on the risk of GC were explored in the present work, and the combined effects were also taken into account. Confounders were controlled by PS adjustment. Substantial evidence has strongly suggested that GC risk may be decreased with a high intake of vegetables [44]. As expected, significant combined effects between ZNF331 methylation and the intake of green vegetables were observed in this study. Green vegetables are rich in polyphenol compounds, which possess anti-cancer effects through alterations in DNA methylation, histone modifications and miRNA expression [45]. Additionally, increased consumption of garlic has been reported to reduce the risk of GC [46], which may explain the combined effects of garlic consumption and ZNF331 methylation on GC risk. It has been found that organosulfur compounds that naturally exist in garlic could inhibit benzo [a]pyrene-induced neoplasia in the forestomach of mice [47]. Another study has shown that S-allylcysteine derived from garlic could inhibit the expression of DNA methyltransferase 1 and then induce global DNA hypomethylation in human ovarian cancer cells [48]. However, interactions between the intake of green vegetables and garlic and ZNF331 methylation were not found in this study.

Growing evidence has revealed that there is agerelated accumulation of DNA methylation during tumourigenesis [49] and that DNA methylation patterns in blood between men and women exhibit considerable differences [50]. In addition, $H$. pylori and the inflammatory response it triggers may facilitate carcinogenesis in gastric epithelial cells by inducing dysregulation of DNA methylation in the promoter regions of various genes [51, 52]. Given the points mentioned above, we performed subgroup analyses according to age, sex and $H$. pylori infection. The results indicated that ZNF331 methylation was significantly correlated with GC only in males, which to some extent illustrates the sex-related methylation differences. There were also marginal correlations between ZNF331 methylation and GC within both the younger and older groups, WIF1 methylation and GC risk in the younger group, and ZNF331 methylation and GC risk in the $H$. pylori-negative group.

The prognostic effect of ZNF331 and WIF1 methylation was also evaluated in the present work. The results concluded that tumour size and tumour stage could independently influence GC prognosis. It has been reported that colorectal cancer patients with ZNF331 methylation have poor overall survival $[16,17]$, and WIF1 methylation is negatively correlated with prognosis in oesophageal cancer [22]. However, no association was found between candidate gene methylation and GC prognosis.

MS-HRM has been proposed to be a rapid and costeffective way to measure methylation levels in a large panel of samples, and the detection limit can be as low as $0.1 \%$ of gene methylation [53-56]. Moreover, our previous studies have demonstrated the stability and reliability of the MS-HRM assay, which is feasible for methylation detection in peripheral blood, although the methylation levels measured by MS-HRM were relatively lower than those measured by pyrosequencing $[57,58]$. It is also worth noting that the potential nondifferential misclassification bias due to the underestimation of gene methylation levels may have resulted in smaller but still significant effect sizes [59-61]. Nevertheless, we recognized the limitations of the MS-HRM method used in this study that it can only give a semiquantitative estimation of the DNA methylation level, and the results estimated from heterogeneously methylated samples are largely qualitative. Thus, further validations by sequencing methodologies or other available techniques are necessary for future work.

This study also has several other limitations. First, we could not elucidate the chronological order of gene methylation and GC due to the retrospective nature of this study. Second, recall bias may have affected our results, although efforts were made to minimize this bias. Third, dietary factors were collected by frequency rather than quantity, which might influence the efficiency of the analysis.

\section{Conclusion}

In summary, this study uncovered that ZNF331 methylation in PBLs was correlated with the risk of GC. The combined effects between ZNF331 methylation and high intakes of green vegetables and garlic might decrease the risk of GC.

\section{Abbreviations \\ PBL: Peripheral blood leukocyte; GC: Gastric cancer; ZNF331: Zinc-finger protein 331; WIF1: Wnt-inhibitory factor-1; MS-HRM: Methylation-sensitive high-resolution melting; PS: Propensity score; Hm: High methylation; Lm: Low methylation; Hom: Homogeneous methylation; Hem: Heterogeneous methylation; ORs: Odds ratios; Cls: Confidence intervals; HRs: Hazard ratios; BMI: Body mass index; TNM: Tumour node metastasis; CEA: Carcinoembryonic antigen; CA 19-9: Carbohydrate antigen 19-9}

\section{Supplementary Information}

The online version contains supplementary material available at https://doi. org/10.1186/s12885-021-08199-4.

Additional file 1: Table S1. Detailed information of the amplified regions and primer sequences and the reaction conditions for methylation-sensitive high-resolution melting (MS-HRM) assay. 
Additional file 2: Figure S1. Receiver operating characteristic curve and the corresponding area under the curve (AUC) analyses of ZNF331 methylation on gastric cancer risk.

Additional file 3: Figure S2. The normalized melting curves and melting peaks of homogeneous methylation (Hom) and heterogeneous methylation (Hem) for WIFT.

Additional file 4: Figure S3. The distribution of ZNF331 (a) and WIF1 (b) methylation status in GC cases and controls.

Additional file 5: Table S2. Association between environmental factors and GC risk.

Additional file 6: Table S3. Multivariate analysis and internal validation of the association between environmental factors and GC risk.

Additional file 7: Table S4. Association between the methylation status of genes and GC risk by stratified analysis.

Additional file 8: Table S5. Association between ZNF331 and WIF1 methylation and environmental factors.

Additional file 9: Table S6. Effects of the combination between environmental factors and ZNF331 methylation status on GC risk in the whole population and internal validation datasets.

Additional file 10: Table S7. Effects of the combination and interaction between environmental factors and ZNF331 methylation status on GC risk.

Additional file 11: Table S8. Effects of the combination and interaction between environmental factors and WIF1 methylation status on $\mathrm{GC}$ risk.

Additional file 12: Table S9. Effects of the combination and interaction between ZNF331 and WIF1 methylation on GC risk.

Additional file 13: Table S10. Association between demographic characteristics and GC prognosis.

Additional file 14: Table S11. Association between clinical characteristics and GC prognosis.

Additional file 15: Table S12. Multivariate analysis of GC prognosis. Additional file 16: Figure S4. Survival curves of the association between ZNF331 (a) and WIF1 (b) methylation and GC prognosis.

Additional file 17: Table S13. Association between the methylation status of genes and GC prognosis by stratified analysis.

\section{Acknowledgements}

The authors thank all the participants for donating blood samples and all the researchers for their contributions to this work.

\section{Authors' contributions}

WT and $\mathrm{HZ}$ conceived and designed the study, and critically revised the manuscript. CN analyzed the data and drafted the manuscript. $\mathrm{CN}, \mathrm{XH}$ and RW performed the experiments. $C N, X H, R W, A L, J H, X D$ and JW collected samples. $\mathrm{LZ}$ and $Y Z$ participated in study design and provided technical support. YX provided samples. All authors approved the final manuscript submitted for publication.

\section{Funding}

This work was supported by grants from the Heilongjiang Provincial Natural Science Foundation of China ( $(\mathrm{H} 2 \mathrm{O} 2 \mathrm{OH} 020)$ and the Postgraduate Research and Practice Innovation Project of Harbin Medical University (YJSKYCX2019$75 \mathrm{HYD})$.

\section{Availability of data and materials}

The datasets generated and/or analysed during the current study are not publicly available because the project is currently under study but are available from the corresponding author upon reasonable request.

\section{Declarations}

Ethics approval and consent to participate

The study was approved by the Human Research and Ethics Committee of Harbin Medical University. All participants had given written informed consent.

\section{Consent for publication}

Not applicable.

\section{Competing interests}

The authors declare that they have no conflicts of interest.

\section{Author details}

${ }^{1}$ Department of Epidemiology, School of Public Health, Harbin Medical University, Harbin, 157 Baojian Road, Harbin 150081, Heilongjiang Province, People's Republic of China. ${ }^{2}$ Department of Gastroenterological Surgery, Third Affiliated Hospital of Harbin Medical University, 150 Haping Road, Harbin 150081, Heilongjiang Province, People's Republic of China.

Received: 11 January 2021 Accepted: 14 April 2021

Published online: 15 May 2021

\section{References}

1. Bray F, Ferlay J, Soerjomataram I, Siegel RL, Torre LA, Jemal A. Global cancer statistics 2018: GLOBOCAN estimates of incidence and mortality worldwide for 36 cancers in 185 countries. CA Cancer J Clin. 2018;68(6):394-424. https://doi.org/10.3322/caac.21492.

2. Karimi P, Islami F, Anandasabapathy S, Freedman ND, Kamangar F. Gastric cancer: descriptive epidemiology, risk factors, screening, and prevention. Cancer Epidemiol Biomark Prev. 2014;23(5):700-13. https://doi.org/10.1158/1 055-9965.EPI-13-1057.

3. Wolffe AP, Matzke MA. Epigenetics: regulation through repression. Science. 1999:286(5439):481-6. https://doi.org/10.1126/science.286.5439.481.

4. Jones PA, Baylin SB. The fundamental role of epigenetic events in cancer. Nat Rev Genet. 2002;3(6):415-28. https://doi.org/10.1038/nrg816.

5. Feinberg AP, Tycko B. The history of cancer epigenetics. Nat Rev Cancer. 2004;4(2):143-53. https://doi.org/10.1038/nrc1279.

6. Hon GC, Hawkins RD, Caballero OL, Lo C, Lister R, Pelizzola M, et al. Global DNA hypomethylation coupled to repressive chromatin domain formation and gene silencing in breast cancer. Genome Res. 2012;22(2):246-58. https://doi.org/10.1101/gr.125872.111

7. Esteller M, Corn PG, Baylin SB, Herman JG. A gene hypermethylation profile of human cancer. Cancer Res. 2001;61(8):3225-9.

8. Koch A, Joosten SC, Feng Z, de Ruijter TC, Draht MX, Melotte V, et al. Analysis of DNA methylation in cancer: location revisited. Nat Rev Clin Oncol. 2018;15(7):459-66. https://doi.org/10.1038/s41571-018-0004-4.

9. Arasaradnam RP, Commane DM, Bradburn D, Mathers JC. A review of dietary factors and its influence on DNA methylation in colorectal carcinogenesis. Epigenetics. 2008;3(4):193-8. https://doi.org/10.4161/epi.3.4 6508.

10. Herceg Z. Epigenetics and cancer: towards an evaluation of the impact of environmental and dietary factors. Mutagenesis. 2007;22(2):91-103. https://doi.org/10.1093/mutage/gel068.

11. Herceg Z, Vaissiere T. Epigenetic mechanisms and cancer: an interface between the environment and the genome. Epigenetics. 2011;6(7):804-19. https://doi.org/10.4161/epi.6.7.16262.

12. Rippe $V$, Belge $G$, Meiboom M, Kazmierczak B, Fusco A, Bullerdiek J. A KRAB zinc finger protein gene is the potential target of $19 q 13$ translocation in benign thyroid tumors. Genes Chromosomes Cancer. 1999;26(3):229-36. https://doi.org/10.1002/(SICI)1098-2264(199911)26:3<229::AID-GCC7>3.0. $\mathrm{CO} ; 2-\mathrm{J}$.

13. Witzgall R, O'Leary E, Leaf A, Onaldi D, Bonventre JV. The Kruppel-associated box-A (KRAB-A) domain of zinc finger proteins mediates transcriptional repression. Proc Natl Acad Sci U S A. 1994;91(10):4514-8. https://doi.org/10.1 073/pnas.91.10.4514

14. Yu J, Liang QY, Wang J, Cheng Y, Wang S, Poon TC, et al. Zinc-finger protein 331, a novel putative tumor suppressor, suppresses growth and invasiveness of gastric cancer. Oncogene. 2013:32(3):307-17. https://doi. org/10.1038/onc.2012.54. 
15. Vedeld HM, Andresen K, Eilertsen IA, Nesbakken A, Seruca R, Gladhaug IP, et al. The novel colorectal cancer biomarkers CDO1, ZSCAN18 and ZNF331 are frequently methylated across gastrointestinal cancers. Int J Cancer. 2015; 136(4):844-53. https://doi.org/10.1002/ijc.29039.

16. Vedeld HM, Nesbakken A, Lothe RA, Lind GE. Re-assessing ZNF331 as a DNA methylation biomarker for colorectal cancer. Clin Epigenetics. 2018;10(1):70. https://doi.org/10.1186/s13148-018-0503-2.

17. Wang Y, He T, Herman JG, Linghu E, Yang Y, Fuks F, et al. Methylation of ZNF331 is an independent prognostic marker of colorectal cancer and promotes colorectal cancer growth. Clin Epigenetics. 2017;9(1):115. https:// doi.org/10.1186/s13148-017-0417-4.

18. Hsieh JC, Kodjabachian L, Rebbert ML, Rattner A, Smallwood PM, Samos CH, et al. A new secreted protein that binds to Wnt proteins and inhibits their activities. Nature. 1999;398(6726):431-6. https://doi.org/10.1038/18899.

19. Poggi L, Casarosa S, Carl M. An eye on the Wnt inhibitory factor Wif1. Front Cell Dev Biol. 2018;6:167. https://doi.org/10.3389/fcell.2018.00167.

20. Taniguchi H, Yamamoto H, Hirata T, Miyamoto N, Oki M, Nosho K, et al. Frequent epigenetic inactivation of Wht inhibitory factor-1 in human gastrointestinal cancers. Oncogene. 2005;24(53):7946-52. https://doi.org/10.1 038/sj.onc.1208910.

21. Guo H, Zhou S, Tan L, Wu X, Wu Z, Ran R. Clinicopathological significance of WIF1 hypermethylation in NSCLC, a meta-analysis and literature review. Oncotarget. 2017;8(2):2550-7. https://doi.org/10.18632/oncotarget.13707.

22. Guo Q, Wang HB, Li YH, Li HF, Li TT, Zhang WX, et al. Correlations of promoter methylation in WIF-1, RASSF1A, and CDH13 genes with the risk and prognosis of esophageal cancer. Med Sci Monit. 2016;22:2816-24. https://doi.org/10.12659/MSM.896877.

23. Liu P, Shen JK, Hornicek FJ, Liu F, Duan Z. Wnt inhibitory factor 1 (WIF1) methylation and its association with clinical prognosis in patients with chondrosarcoma. Sci Rep. 2017;7(1):1580. https://doi.org/10.1038/s41598-01 7-01763-8.

24. Li L, Choi JY, Lee KM, Sung H, Park SK, Oze I, et al. DNA methylation in peripheral blood: a potential biomarker for cancer molecular epidemiology. J Epidemiol. 2012;22(5):384-94. https://doi.org/10.2188/jea.JE20120003.

25. Yuasa Y. Epigenetics in molecular epidemiology of cancer a new scope. Adv Genet. 2010;71:211-35. https://doi.org/10.1016/B978-0-12-380864-6.00007-9.

26. Dauksa A, Gulbinas A, Endzinas Z, Oldenburg J, El-Maarri O. DNA methylation at selected $\mathrm{CpG}$ sites in peripheral blood leukocytes is predictive of gastric cancer. Anticancer Res. 2014;34(10):5381-8.

27. Yuasa Y, Nagasaki H, Oze I, Akiyama Y, Yoshida S, Shitara K, et al. Insulin-like growth factor 2 hypomethylation of blood leukocyte DNA is associated with gastric cancer risk. Int J Cancer. 2012;131(11):2596-603. https://doi. org/10.1002/ijc.27554.

28. Zhang Y, Su HJ, Pan KF, Zhang L, Ma JL, Shen L, et al. Methylation status of blood leukocyte DNA and risk of gastric cancer in a high-risk Chinese population. Cancer Epidemiol Biomark Prev. 2014;23(10):2019-26. https:// doi.org/10.1158/1055-9965.EPI-13-0994.

29. Sun H, Zhou H, Zhang Y, Chen J, Han X, Huang D, et al. Aberrant methylation of FAT4 and SOX11 in peripheral blood leukocytes and their association with gastric cancer risk. J Cancer. 2018;9(13):2275-83. https://doi. org/10.7150/jca.24797.

30. Shu XO, Yang G, Jin F, Liu D, Kushi L, Wen W, et al. Validity and reproducibility of the food frequency questionnaire used in the Shanghai Women's health study. Eur J Clin Nutr. 2004;58(1):17-23. https://doi.org/10.1 038/sj.ejcn.1601738.

31. Candiloro IL, Mikeska T, Hokland P, Dobrovic A. Rapid analysis of heterogeneously methylated DNA using digital methylation-sensitive high resolution melting: application to the CDKN2B (p15) gene. Epigenetics Chromatin. 2008;1(1):7. https://doi.org/10.1186/1756-893 5-1-7.

32. Li L, Zheng H, Huang Y, Huang C, Zhang S, Tian J, et al. DNA methylation signatures and coagulation factors in the peripheral blood leucocytes of epithelial ovarian cancer. Carcinogenesis. 2017;38(8):797-805. https://doi. org/10.1093/carcin/bgx057.

33. Jiang S, Linghu E, Zhan Q, Han W, Guo M. Methylation of ZNF331 promotes cell invasion and migration in human esophageal cancer. Curr Protein Pept Sci. 2015;16(4):322-8. https://doi.org/10.2174/138920371604150429155255.

34. Teschendorff AE, Menon U, Gentry-Maharaj A, Ramus SJ, Gayther SA Apostolidou S, et al. An epigenetic signature in peripheral blood predicts active ovarian cancer. PLoS One. 2009;4(12):e8274. https://doi.org/10.1371/ journal.pone.0008274.
35. Chen D, Zhang XR, Zhang Y, Zhang L, Ma JL, You WC, et al. Hypomethylation of repetitive elements in blood leukocyte DNA and risk of gastric lesions in a Chinese population. Cancer Epidemiol. 2016;41:122-8. https://doi.org/10.1016/j.canep.2016.02.004.

36. Rusiecki JA, Al-Nabhani M, Tarantini L, Chen L, Baccarelli A, Al-Moundhri MS. Global DNA methylation and tumor suppressor gene promoter methylation and gastric cancer risk in an Omani Arab population. Epigenomics. 2011; 3(4):417-29. https://doi.org/10.2217/epi.11.65.

37. Kaneda A, Tsukamoto T, Takamura-Enya T, Watanabe N, Kaminishi M, Sugimura T, et al. Frequent hypomethylation in multiple promoter CpG islands is associated with global hypomethylation, but not with frequent promoter hypermethylation. Cancer Sci. 2004;95(1):58-64. https://doi.org/1 0.1111/j.1349-7006.2004.tb03171.x.

38. Lee BB, Lee EJ, Jung EH, Chun H-K, Chang DK, Song SY, et al. Aberrant methylation of APC, MGMT, RASSF2A, and Wif-1 genes in plasma as a biomarker for early detection of colorectal cancer. Clin Cancer Res. 2009; 15(19):6185-91. https://doi.org/10.1158/1078-0432.CCR-09-0111.

39. Roperch J-P, Incitti R, Forbin S, Bard F, Mansour H, Mesli F, et al. Aberrant methylation of NPY, PENK, and WIF1 as a promising marker for blood-based diagnosis of colorectal cancer. BMC Cancer. 2013;13(1):566. https://doi.org/1 0.1186/1471-2407-13-566.

40. Liu X, Fu J, Bi H, Ge A, Xia T, Liu Y, et al. DNA methylation of SFRP1, SFRP2, and WIF1 and prognosis of postoperative colorectal cancer patients. BMC Cancer. 2019;19(1):1212. https://doi.org/10.1186/s12885-019-6436-0.

41. Ajani JA, Lee J, Sano T, Janjigian YY, Fan D, Song S. Gastric adenocarcinoma. Nat Rev Dis Primers. 2017;3(1):17036. https://doi.org/10.1038/nrdp.2017.36.

42. Fang $X$, Wei J, He $X$, An P, Wang $H$, Jiang $L$, et al. Landscape of dietary factors associated with risk of gastric cancer: a systematic review and doseresponse meta-analysis of prospective cohort studies. Eur J Cancer. 2015; 51(18):2820-32. https://doi.org/10.1016/j.ejca.2015.09.010.

43. Ghaffari HR, Yunesian M, Nabizadeh R, Nasseri S, Sadjadi A, Pourfarzi F, et al. Environmental etiology of gastric cancer in Iran: a systematic review focusing on drinking water, soil, food, radiation, and geographical conditions. Environ Sci Pollut Res Int. 2019;26(11):10487-95. https://doi.org/1 0.1007/s11356-019-04493-8.

44. Tsugane S, Sasazuki S. Diet and the risk of gastric cancer: review of epidemiological evidence. Gastric Cancer. 2007;10(2):75-83. https://doi.org/1 0.1007/s10120-007-0420-0.

45. Huang D, Cui L, Ahmed S, Zainab F, Wu Q, Wang X, et al. An overview of epigenetic agents and natural nutrition products targeting DNA methyltransferase, histone deacetylases and microRNAs. Food Chem Toxicol. 2019;123:574-94. https://doi.org/10.1016/j.fct.2018.10.052.

46. Zhou Y, Zhuang W, Hu W, Liu GJ, Wu TX, Wu XT. Consumption of large amounts of Allium vegetables reduces risk for gastric cancer in a metaanalysis. Gastroenterology. 2011;141(1):80-9. https://doi.org/10.1053/j.ga stro.2011.03.057.

47. Sparnins VL, Barany G, Wattenberg LW. Effects of organosulfur compounds from garlic and onions on benzo [a]pyrene-induced neoplasia and glutathione S-transferase activity in the mouse. Carcinogenesis. 1988;9(1): 131-4. https://doi.org/10.1093/carcin/9.1.131.

48. Xu Y, Su D, Zhu L, Zhang S, Ma S, Wu K, et al. S-allylcysteine suppresses ovarian cancer cell proliferation by DNA methylation through DNMT1. J Ovarian Res. 2018;11(1):39. https://doi.org/10.1186/s13 048-018-0412-1.

49. Jung M, Pfeifer GP. Aging and DNA methylation. BMC Biol. 2015;13(1):7. https://doi.org/10.1186/s12915-015-0118-4.

50. Lin S, Liu Y, Goldin LR, Lyu C, Kong X, Zhang Y, et al. Sex-related DNA methylation differences in B cell chronic lymphocytic leukemia. Biol Sex Differ. 2019;10(1):2. https://doi.org/10.1186/s13293-018-0213-7.

51. Woo HD, Fernandez-Jimenez N, Ghantous A, Degli Esposti D, Cuenin C, Cahais $V$, et al. Genome-wide profiling of normal gastric mucosa identifies helicobacter pylori- and cancer-associated DNA methylome changes. Int J Cancer. 2018;143(3):597-609. https://doi.org/10.1002/ijc.31381.

52. Muhammad JS, Eladl MA, Khoder G. Helicobacter pylori-induced DNA methylation as an epigenetic modulator of gastric cancer: recent outcomes and future direction. Pathogens. 2019;8(1):23. https://doi.org/10.3390/pa thogens8010023.

53. Wojdacz TK, Dobrovic A. Methylation-sensitive high resolution melting (MSHRM): a new approach for sensitive and high-throughput assessment of methylation. Nucleic Acids Res. 2007;35(6):e41. https://doi.org/10.1093/nar/ gkm013. 
54. Wojdacz TK, Borgbo T, Hansen LL. Primer design versus PCR bias in methylation independent PCR amplifications. Epigenetics. 2009;4(4):231-4. https://doi.org/10.4161/epi.9020.

55. Wong EM, Dobrovic A. Assessing gene-specific methylation using HRMbased analysis. Methods Mol Biol. 2011;687:207-17. https://doi.org/10.1007/ 978-1-60761-944-4_14.

56. Hussmann D, Hansen LL. Methylation-sensitive high resolution melting (MSHRM). Methods Mol Biol. 2018;1708:551-71.

57. Liu Y, Wang Y, Hu F, Sun H, Zhang Z, Wang $X$, et al. Multiple gene-specific DNA methylation in blood leukocytes and colorectal cancer risk: a casecontrol study in China. Oncotarget. 2017;8(37):61239-52. https://doi.org/10.1 8632/oncotarget.18054.

58. Gao HL, Wang X, Sun HR, Zhou JD, Lin SQ, Xing YH, et al. Methylation status of transcriptional modulatory genes associated with colorectal cancer in Northeast China. Gut Liver. 2018;12(2):173-82. https://doi.org/10.5009/gnl1 7163.

59. Dosemeci M, Wacholder S, Lubin JH. Does nondifferential misclassification of exposure always bias a true effect toward the null value? Am J Epidemiol. 1990;132(4):746-8. https://doi.org/10.1093/oxfordjournals.aje.a11 5716.

60. Flegal KM, Brownie C, Haas JD. The effects of exposure misclassification on estimates of relative risk. Am J Epidemiol. 1986;123(4):736-51. https://doi. org/10.1093/oxfordjournals.aje.a114294.

61. Copeland KT, Checkoway H, McMichael AJ, Holbrook RH. Bias due to misclassification in the estimation of relative risk. Am J Epidemiol. 1977; 105(5):488-95. https://doi.org/10.1093/oxfordjournals.aje.a112408.

\section{Publisher's Note}

Springer Nature remains neutral with regard to jurisdictional claims in published maps and institutional affiliations.

Ready to submit your research? Choose BMC and benefit from:

- fast, convenient online submission

- thorough peer review by experienced researchers in your field

- rapid publication on acceptance

- support for research data, including large and complex data types

- gold Open Access which fosters wider collaboration and increased citations

- maximum visibility for your research: over $100 \mathrm{M}$ website views per year

At $\mathrm{BMC}$, research is always in progress.

Learn more biomedcentral.com/submissions 